\title{
Genome-wide identification of MADS-box gene family in sacred lotus (Nelumbo nucifera) identifies a SEPALLATA homolog gene involved in floral development
}

\author{
Zhongyuan Lin ${ }^{1,2}$, Dingding Cao ${ }^{2}$, Rebecca Njeri Damaris ${ }^{1}$ and Pingfang Yang ${ }^{1 *}$ (D)
}

\begin{abstract}
Background: Sacred lotus (Nelumbo nucifera) is a vital perennial aquatic ornamental plant. Its flower shape determines the horticultural and ornamental values. However, the mechanisms underlying lotus flower development are still elusive. MADS-box transcription factors are crucial in various features of plant development, especially in floral organogenesis and specification. It is still unknown how the MADS-box transcription factors regulate the floral organogenesis in lotus.
\end{abstract}

Results: To obtain a comprehensive insight into the functions of MADS-box genes in sacred lotus flower development, we systematically characterized members of this gene family based on the available genome information. A total of 44 MADSbox genes were identified, of which 16 type I and 28 type II genes were categorized based on the phylogenetic analysis. Furthermore, the structure of MADS-box genes and their expressional patterns were also systematically analyzed. Additionally, subcellular localization analysis showed that they are mainly localized in the nucleus, of which a SEPALLATA3 (SEP3) homolog NnMADS14 was proven to be involved in the floral organogenesis.

Conclusion: These results provide some fundamental information about the MADS-box gene family and their functions, which might be helpful in not only understanding the mechanisms of floral organogenesis but also breeding of high ornamental value cultivars in lotus.

Keywords: Floral organogenesis, Genome-wide analysis, Lotus, MADS-box, SEP3

\section{Background}

Nelumbonaceae is one of the smallest families in flowering plants, which consists of only two species named as Nelumbo nucifera Gaertn. and Nelumbo lutea Pers, respectively $[1,2]$. $N$. nucifera is also called sacred lotus in Asia based on its significance in Buddhism and Hinduism [3]. Besides, lotus is also an important horticultural plant with ornamental, nutritional, and medicinal values [3]. In

\footnotetext{
* Correspondence: yangpf@hubu.edu.cn

'State Key Laboratory of Biocatalysis and Enzyme Engineering, School of Life Sciences, Hubei University, Wuhan 430062, China

Full list of author information is available at the end of the article
}

reality, there are three major categories of lotus, namely flower, seed, and rhizome lotus. Flower lotus is a very important aquatic ornamental plant in Southeast Asia because of its variable flower color and shape, which is among the top ten famous flowers in China. Flower shape is largely determined by the arrangement of its four basic constitutive organs, sepals, petals, stamens, and carpels. The petal number, size, and shape contribute greatly to the flower shape. In lotus, there are many transition petal shapes. Based on lotus flower morphology, there are four groups, named as few-petalled, double-petalled, duplicatepetalled, and all-double-petalled, respectively $[1,2]$.

C C The Author(s). 2020 Open Access This article is licensed under a Creative Commons Attribution 4.0 International License, which permits use, sharing, adaptation, distribution and reproduction in any medium or format, as long as you give appropriate credit to the original author(s) and the source, provide a link to the Creative Commons licence, and indicate if changes were made. The images or other third party material in this article are included in the article's Creative Commons licence, unless indicated otherwise in a credit line to the material. If material is not included in the article's Creative Commons licence and your intended use is not permitted by statutory regulation or exceeds the permitted use, you will need to obtain permission directly from the copyright holder. To view a copy of this licence, visit http://creativecommons.org/licenses/by/4.0/. The Creative Commons Public Domain Dedication waiver (http://creativecommons.org/publicdomain/zero/1.0/) applies to the data made available in this article, unless otherwise stated in a credit line to the data. 
Petaloid is one of the key features that are selected in the breeding of ornamental plants, based on which numerous lotus cultivars showing petaloid differentiation, such as stamen petaloid and carpel petaloid have been obtained. This petal shape transition feature makes lotus an ideal plant for studying floral development, especially floral organogenesis.

Since the identification of the first key transcription factors (TFs) in floral organogenesis [4], a series of TFs controlling floral organ specification have been characterized, which have resulted in the well-known classic 'ABC/DE' model [511]. Different combination of $A, B, C$, and $E$ classes genes determines the floral organ specification, such as sepals, petal, stamen, carpel, and ovule controlled by $\mathrm{A}+\mathrm{E}, \mathrm{A}+\mathrm{B}+\mathrm{E}, \mathrm{B}+$ $\mathrm{C}+\mathrm{E}, \mathrm{C}+\mathrm{E}$, and $\mathrm{D}+\mathrm{E}$, respectively [12-15]. A subset of functional genes in this model is comprised of class A (APET ALA1/FRUITFULL, AP1/FUL), class B (APETALA3/PISTILLATA, AP3/PI), class C/D (AGAMOUS/SEEDSTICK/SHATTERPROOF1/2, AG/STK/SHP1/2), and class E (SEP1/2/3/4) $[9,13,16]$.

Except for a putative A-class gene APETALA2 (AP2), all the other known $\mathrm{A}, \mathrm{B}, \mathrm{C}$, and $\mathrm{E}$ class genes encode MADS-box proteins [8, 17, 18]. The acronym MADS box stands for the initials of four loci, MINICHROMOSOME MAINTENANCE (MCM1) of yeast, AGAMOUS (AG) of Arabidopsis thaliana, DEFICIENS (DEF) of Antirrhinum majus, and SERUM RESPONSE FACTOR (SRF) of Homo sapiens, of which all members contain a conserved 58-60 amino acids M-domain region in the $\mathrm{N}$-terminus [19]. In eukaryote, the MADS-box gene family is ubiquitous for development control [19]. Phylogeny divides the MADS-box gene family in two clades, type I and type II, which contain genes with SRF-like MADS domains or MYOCYTE ENHANCER FACTOR 2 like (MEF2-like) domains [20]. Type I MADS-box genes can be further classified into $M \alpha, M \beta$, and $M \gamma$, whereas the type II MADS-box genes only exist in the plant kingdom [21] and are further categorized into MIKC $^{\mathrm{C}}$ and MIKC $\mathrm{C}^{*}$ based on structure divergence of the intervening (I) region [20, 22]. In addition to MADSdomain (M), MIKC-type proteins generally contain another three common domain structures, including intervening (I) domain, keratin-like (K) domain, and Cterminal $(C)$ domain, which together interact with other components and bind to CArG box to activate the expression of the downstream genes [15, 22-24].

Previous studies have shown the ubiquitous functions of MIKC ${ }^{\mathrm{C}}$ genes in plant development [25-29]. Several MIKC ${ }^{\mathrm{C}}$ genes, such as AGAMOUS like 24 (AGL24) and SHORT VEGETATIVE PHASE (SVP), FLOWERING LOCUS C (FLC) and MADS AFFECTING FLOWERING (MAF1/FLM), AGL15 and AGL18, and SUPPRESSOR OF OVEREXPRESSION OF CONSTANS 1 (SOC1) were shown to control flowering time in Arabidopsis [30-34].
TRANSPARENT TESTA16 (TT16) gene is involved in the pigmentation of the seed coat and embryo development [35]. AGL6 genes play numerous roles in floral meristem regulation, floral organ, seed development, and male and female floral organ development [36]. Some of them also regulate the vegetative growth, such as AGL12 is important in root development as well as in flowering transition [37], and AGL17-clade homolog genes regulate lateral root development $[28,38]$.

Because of their important roles in plant development, especially in floral organogenesis, characterizing the functions of different MADS-box genes has been one of the hotspots in plant biology community. To achieve this, systematic genome-wide analysis of MADS-box gene family is necessary, which have been widely conducted in many plants, such as Arabidopsis [22], rice [39], Brassica rapa [40], orchid [41], grapevine [42], and Rosa chinensis [11]. For lotus, the genome has recently been sequenced and released [43, 44], which facilitates further study on function characterization of gene or gene family. Similar studies have been conducted on the bHLH, R2R3 MYB, and GARS transcription factor families [45-47]. However, a genome-wide systematic analysis on the MADS-box gene family in lotus is absent, although few studies have been conducted focusing on some specific members of this gene family, including the APETALA1-like gene [48] and other floral organ identity MADS-box genes [49]. To obtain more comprehensive insight about the functions of MADS-box gene family in lotus development, especially in controlling its flower shape, we conducted a genomewide identification of MADS-box genes, and systematically analyzed their distribution, phylogenetic relationship, gene structure, and expression profiles in the sequenced sacred lotus 'China Antique'. Certain candidate MADSbox genes that might be involved in floral organ formation were selected for further analyses, of which a SEP3 homolog was proven to be involved in the floral organ specification. These results might help to further understand the function of this gene family, especially in lotus flower development.

\section{Results}

Identification of MADS-box genes and their distribution in lotus genome

To obtain a general knowledge on MADS-box gene family in lotus, we first searched for them in the lotus genome database to determine the number of genes in this family [50]. A set of 52 candidates annotated as MADS-box genes (Table S1) were retrieved. Meanwhile, after biosequence analysis, the same number of putative MADSbox proteins was also derived. To accurately determine the members, after removing the candidates that aligned to the same sequence ID in NCBI (Table S1), a total of 44 $N$. nucifera MADS-box genes (NnMADS1-44) were 
confirmed by annotating them with Arabidopsis MADSbox gene names [22], of which some contained different transcript variants (Table S1). Some of them had segmental or tandem duplications (Table S2). Their nonsynonymous $(K a)$ and synonymous $(K s)$ substitution rates were analyzed (Table S2) and the $\mathrm{Ka} / \mathrm{Ks}$ ratio values were nearly close to one.

Lotus genome has been assembled into megascaffolds, including nine big and several small ones [43]. Among all the confirmed NnMADS genes, 36 were distributed in the top ten biggest megascaffolds 1-10 (Fig. S1a), and the remaining 8 genes were anchored in other small megascaffolds (Fig. S1b). Except for megascaffolds 3 and 7 that did not contain any NnMADS gene, megascaffold 2 , one of the top largest megascaffolds $(133.00 \mathrm{Mb})$ contained seven NnMADS genes; megascaffolds 1, 4, 5, and 6 all had 5 members (Fig. S1b). Similar to the distribution of R2R3 MYB [51], the density of MADS-box genes in the megascaffold is not uniform. Megascaffold 4 was the densest with 9.24 Mb/MADS-box gene while megascaffold 1 had the minimum density ( $51.00 \mathrm{Mb} /$ gene) (Fig. S1c).

\section{Phylogenetic analysis of $N$. nucifera MADS-box genes}

To-date, MADS-box genes in the genomes of 34 other plant species have been reported and summarized [40, 41, 52]. Among all the listed plant species, lotus contains a relatively small family of MADS-box genes (Fig. 1a), which is comparable with other basal species (Fig. 1a). To obtain a more comprehensive insight on this gene family in lotus, the full length of each MADS-box gene of lotus, Arabidopsis, and rice were downloaded from the NCBI database for further category and phylogenetic analyses. Based on the analysis of BLASTP against TAIR database, there were 16 type I (including nine $M \alpha$, two $M \beta$, and five $M \gamma$ ) and 28 type II (including $25 \mathrm{MIKC}^{\mathrm{C}}$ and three MIKC*) MADS-box proteins in lotus (Fig. 1a and Table S1), and all the predicted MADSbox proteins contained different transcript variants belonging to MIKC $^{\mathrm{c}}$ (Table S1). Meanwhile, we also constructed the phylogenetic tree using sequences of all the predicted MADS-box proteins from the three species (Fig. 1b). The 25 MIKC $^{\mathrm{c}}$ type NnMADS genes (Fig. 1b) could be further grouped into twelve subfamilies: SOC1, AGL6, A (AP1/ FUL), B (AP3/PI), C/D (AG/STK/SHP1/2), E (SEP), SVP, AGL12, AGL15, AGL17, TT6 (B sister), and FLC (Fig. 1b and Table S3). However, the FLC-like gene was absent in lotus (Fig. 1b). The subclade B included four members, both $\mathrm{A}$ and $\mathrm{E}$ contained three while the rest subclades contained two members except for AGL12 that had only one member (Fig. 1b and Table S3).

\section{Analysis of genes structure and conserved motifs}

To investigate the gene structure of MADS-box genes in lotus, the full lengths of cDNA and genomic DNA sequences of $44 \mathrm{NnMADS}$ genes obtained from NCBI database were used for phylogenetic analysis alone, which is consistent with that along with the data from Arabidopsis and rice (Fig. 1b; Fig. 2a). The structures of these $M A D S$ genes could also show the phylogenetic relationship among them (Fig. 2b). Except for NnMADS3 with only one exon, all the other MIKC-type (Type II) genes had an exon-intron structure with more than six exons (Fig. 2b). In contrast, there was almost no intron for Type I MADS-box genes, except for NnMADS28 that contained one intron (Fig. 2b).

A total of twenty conserved motifs among the 44 lotus MADS-box proteins were identified with MEME motif search tool (Fig. 2c). Motif 1 exists in 43 members except for NnMADS43, which contained only one motif (Fig. 2c). Motif 2 and 7 were present in all MIKC ${ }^{\mathrm{C}}$ MADS-box proteins except for NnMADS9 which lacked motif 2 (Fig. 2c). The E class (NnMADS7/8) and AGL6 homologous (NnMADS10/ 11) subfamily contained motif 9 , whereas motif 10 and 13 were conserved in SVP subgroup (NnMADS22 and NnMADS23). Motif 16 was considered as the typical B class motif (Fig. 2c). Motif 12 and motif 17 represented individual pattern of preservation among NnMADS1/2/3/4 in clade B class subfamily. In addition, motif 17 was also found in NnMADS24/25, members of the TT16 clade. AG cluster members including NnMADS5/6 contained a special motif 20. Other MADS-box proteins had some specific motifs in the subfamily, though the motifs were inconsistent. Different members of M $\alpha$ type MADS-box genes contained different motif numbers, such as NnMADS26, NnMADS28, and NnMADS32/33/34 contained more than 3 motifs, whereas NnMADS27 and NnMADS29/30/31 had less than two motifs. $M \beta$ and $M \gamma$ groups had two motifs at most. NnMADS39 and NnMADS43 contained one unspecific motif (Fig. 2c).

The conserved core $\mathrm{M}$ region of NnMADS proteins had $\sim 59$ amino acids, which is consistent with those in other species [20]. There are two types of $M$ region named as type I (SRF-like) and type II (MEF-like), respectively. To assess the conservation of $\mathrm{M}$ region among the NnMADS proteins, members of type I and type II were subjected to alignment analysis along with the representatives of each type from Homo sapiens, which showed that both types are highly conserved with type II (MEF-like) being more conserved (Fig. 3).

\section{Spatial expression of NnMADSs in floral organs and} subcellular localization of several members of NnMADSs

The expression of a given gene might be related to its function. To explore the expressional patterns of NnMADSs, the transcriptome data of 16 tissues including leaf, petiole, rhizome (including tip, elongation zone, and internode), root, flower bud, petal, stamen (immature and mature), carpel (immature and mature), receptacle (immature and mature), 

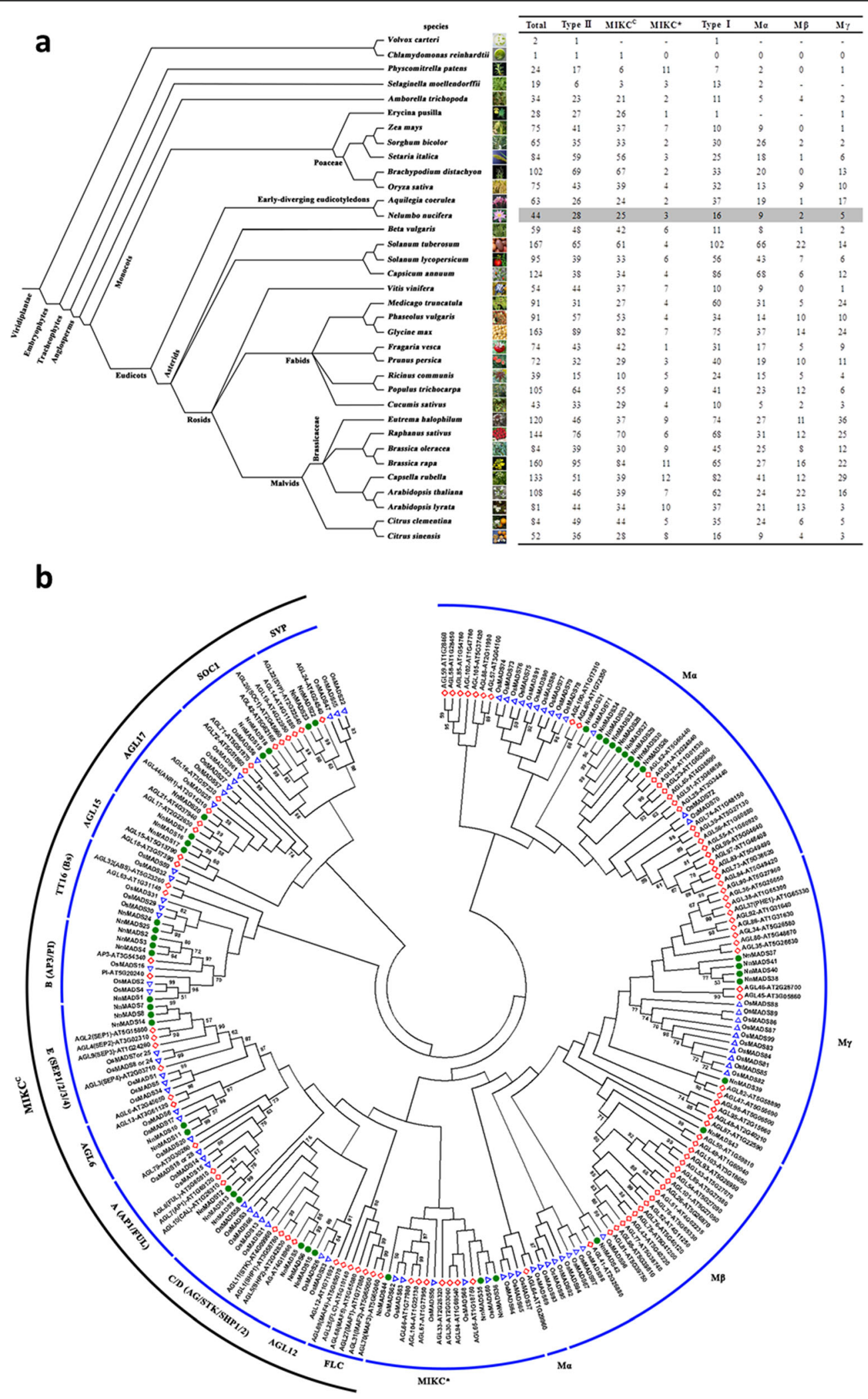

Fig. 1 (See legend on next page.) 
(See figure on previous page.)

Fig. 1 Classification and phylogenetic analyses of MADS-box family genes among different plant species. a The number of MADS-box family genes and their classification in 35 different plant species. The data for lotus, Arabidopsis, and rice are marked in green, red and blue, respectively, which were used for the following phylogenetic analysis. b Phylogenetic analysis of the MADS-box proteins from lotus, Arabidopsis and rice. The phylogenetic tree was constructed with the full-length protein sequences by the neighbor-joining method using MEGA software version 5.2. The digital number on each branch represents bootstrap scores for 1000 replicate analyses. A branch with a bootstrap score below 50 was considered unreliable and cut off. The text out of the blue and black lines represent different types or subtypes of MADS-box proteins

and seed (seed coat and cotyledon) from a previous study were used for further analysis [53]. The data for these 44 NnMADSs were extracted and used to draw a heat-map to show their expression styles (Fig. 4a, Table S4). The type I NnMADS genes generally had low or undetectable expression in all the tissues, except for NnMADS29, NnMADS30, NnMADS40, NnMADS41, and NnMADS43 (Fig. 4a). Both NnMADS29, NnMADS30 belong to Ma subtype and are ubiquitously expressed among different tissues (Fig. 4a). NnMADS40 showed preferential expression in root, rhizome, and cotyledon, NnMADS41 was rhizome internode-specific and NnMADS43 was leaf and petiole specific (Fig. 4a). As for type II NnMADS genes, MIKC" subtype contained two ubiquitously expressed members and one with no detectable expression (Fig. 4a), whereas the MIKC subtype could be categorized into three expressional patterns named as floral organ preferential, vegetative tissue preferential, and ubiquitous patterns (Fig. 4a). The floral organ preferential expressed genes included NnMADS1, NnMADS2, NnMADS4-8, NnMADS10, NnMADS11, NnMADS16, and NnMADS17; vegetative tissue preferential expressed genes included NnMADS9, NnMADS15, NnMADS18, NnMADS19, NnMADS20, and NnMADS23; and the ubiquitous expressed genes included NnMADS12, NnMADS13, and NnMADS22. Specifically, NnMADS24 and NnMADS25 were expressed only in carpel (Fig. 4a). Since we were more concerned with floral organogenesis, qRT-PCR was conducted to confirm the accumulation of those $M I K C^{C}$ subtype $M A D S$ genes (NnMADS1-14) with high expression in the floral organs (Fig. 4b, Table S5). A Comparison between qRT-PCR and RNA-Seq data showed that they were generally consistent with each other (Fig. S2).

Since correct localization of proteins is very important for their functions, the subcellular localization of NnMADS proteins was also investigated through transient transformation of tobacco leaves. We chose several representative MADS-box family members including A class gene (NnMADS12), B class gene (NnMADS1), $\mathrm{C}$ class gene (NnMADS6), E Class genes (NnMADS7, NnMADS14), and AGL6 gene (NnMADS10), and fused them with green fluorescent protein (GFP) for the

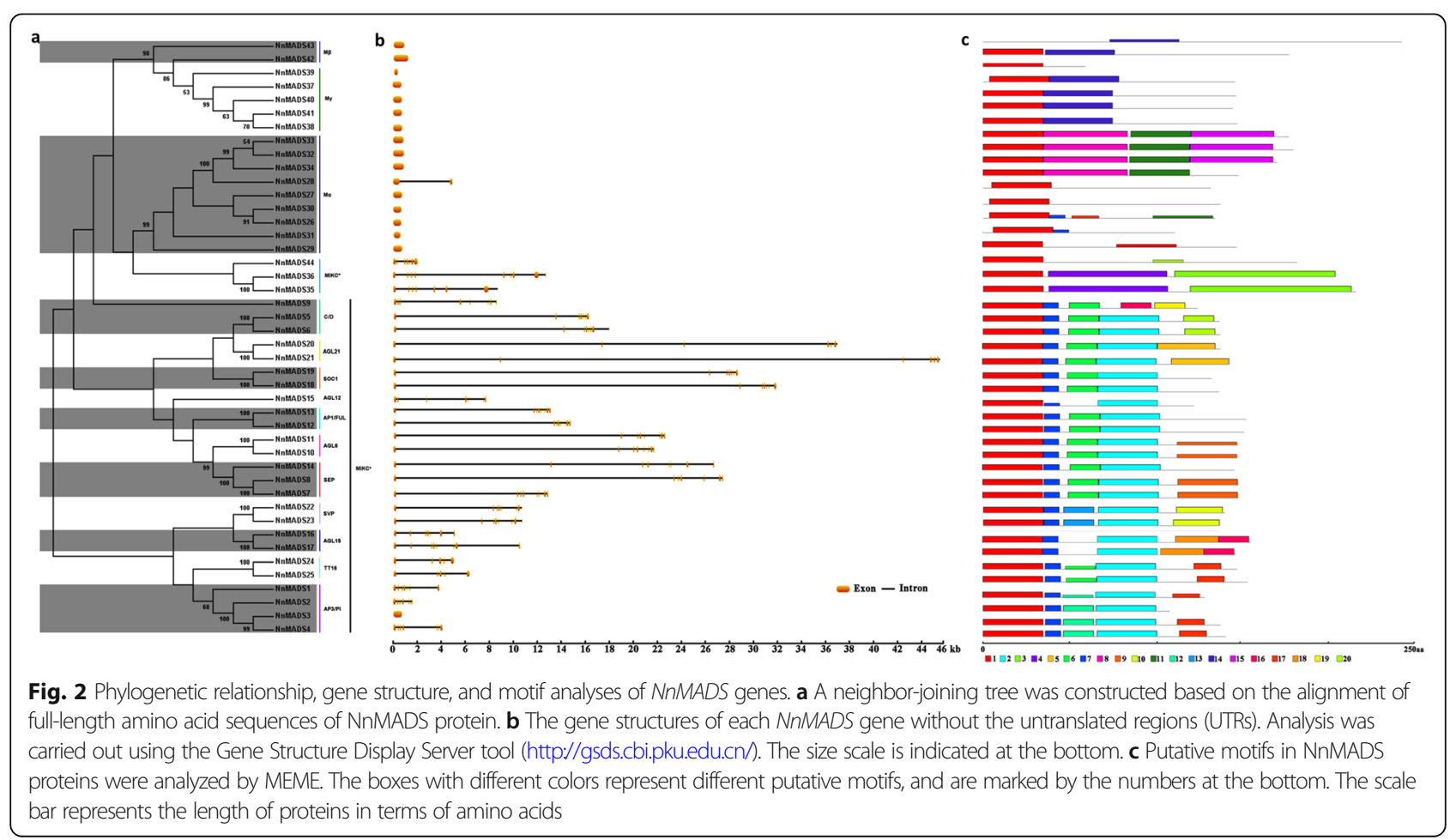




\section{MADS-box MEF like}

20

40

HSMEF2A GRKKIQITR IMDERNRQVTFTKRKFGLMKKAYELS VLCDCEIALII IFNSS NKLFQYAST 59 HsMEF2B GRKKIQ IS R ILDQRNRQVTFTKRKF GLMKKAYELS VLCDCEI A L I I FNS ANRLFQYAST 59 HSMEF2C GRKKIQITR IMDERNRQVTFTKR KF GLMKKAYELS VLCDCEI A L I I FNS T NKLFQYAST 59 HSMEF2D GRKKIQIQR IT DERNRQVTFTKRKFGLMKKAYELS VLCDCE I A L I I FNHS NKLFQYAST 59 NnMADS8 GRGR VELKR I ENK INRQVTFAKRRNGLLKKAYELS VLCDAEVAL I I FS NRGKLYEFCS S 59 NnMADS7 GRGR VELKR I ENK I NRQVT F AKRR NGLLKKAYELS VLCD AEVA I I F S NR GKL YEFCS S 59 NnMADS14 GRGRVELKR I ENK INRQVT FAKRRNGLLKKAYELS VLCDAEVAL I I FS NRGKLYEFCS S 59 NnMADS11 GR GRVELKR I ENK I NRQVTF S KRR NGLLKKA Y E LS VLCDAEVA L I I FS S R GKL YEF GS A 59 NnMADS10 GRGRVELKR I ENK INRQVTFSKRRNGLLKKAYELS VLCDAEVAL I I FS SRGKLYEFGSA 59 NnMADS13 GRGRVQLKR I ENK INRQVTFS KRRNGLLKKAHE IS VLCDAEVAV I VFS TKGKLFEYATD 59 NnMADS12 GR GRVQLKR I ENK INRQVT FS KRRNGLLKKAHE IS VLCDAEVA V I VF S TKGKLFEYATN 59 NnMADS9 GRGRVELKR I EKTTNRQVTFFKRRNGLLKKAFELS I LCDAEVAL I I FSP TGKL YQFANP 59 NnMADS6 GRGK I E I KR I ENT T NRQVT FCKRRNGLLKKA YELS VLCDAEVAL I VFS SRGRLYEYANN 59 NnMADS5 GRGK I E I KR I ENTTNRQVT FCKRRNGLLKKAYELS VLCDAEVALI VFS SRGRLYEYANH 59 NnMADS25 GR GK IEIKR I ENTTNRQVTFS KRRGGLMKKA HELS VLCDAHLGL I I F S S GKMYEYCSS 59 NnMADS24 GRGKIEIKK IENS TNRQVTFS KRRGGLMKKAHELS VLCDAHLGL I I FS S T GKMYEYCS S 59 NnMADS1 GRGKIE I KR I ENS T NRQVT YS KRRNG IMKK AKE I T VLCDAEVS LV I FS S T GKMS E Y CS P 59 NnMADS4 GRGKIEIKR IENS TNRQVTYSKRRGG IFKKAAELTVLCDAEVS L IMFS STGKLS EYVS H 59 NnMADS3 GRGKI E IKR I ENS TNRQVTTSKRRGGIMKKARELT I LCDADVS L IMF S S T GKF S E Y I S H 59 NnMADS2 GRGKIEIKR IENS TNRQVTYSKRRGGIVKKARELTVLCDAEVS LIMFS STGKFS Y IS H 59 NnMADS19 VRGKTQMKR I ENATS RQVTFS KRRNGLLKKAFELS VLCDAEVALI VFS PRGKLYEFSSS 59 NnMADS18 VRGKTQMKR IENATS RQVTFSKRRNGLLKKAFELS VLCDAEVALI VFS PRGKLYEFASS 59 NnMADS21 GRGK I VIRR I DNS TS RQVTFS KRR NGLLKKARELA I LCDAEVGLMI FS S T GKL YDFAS T 59 NnMADS20 GRGK I V I RR I DNS TS RQVT FS KRR NGLLKKARELA I LCDAEVGL I I FS S T GKLYDFAST 59 NnMADS17 GRGK I E IKR I ENATSRQVTFS KRRAGLLKKAQELS I LCDAEVA L I I FS S G GLFEFAS S 59 NnMADS16 GRGK I E IKR I ENATSRQVT FS KRRAGLLKKAQELS I LCDAEVAL I I FS S CGKLFEFASS 59

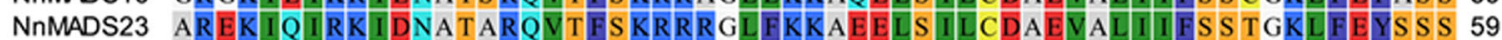
NnMADS22 AREKIQIKKI DNATARQVTFSKRRRGLFKKAEELS I LCDAEVALI I FS ATGKLFEYS S S 59 NnMADS15 ARGKVQMKR I ENTVHRQVTFCKRRAGLLKKAKELS VLCDADVG I I I FS TKGKL YELATK 59 NnMADS44 GRVKLQI KK I ENPTS RQVTFS KRR NGLVKKAYELS VLCDVD I A L I VFF P S GKVNLFS GK 59 NnMADS36 GRVKLKIKRLENTS S RQVTYS KRKNGILKKARELS I LCD I D I AL IMFS P T GKP T LCLGE 59 NnMADS35 GRVKLKIKRLENTS GRQ I T YS KRRT GILKKARELS I LCD I D I ALLMFS P S GKP T LCLGE 59 Consensus GRGK I EIKR I ENXTNRQVTFSKRRNGLLKKAYELSVLCDAEVAL I I FSSTGKLYEYASS

\section{MADS-box SRF like}

20

SRF NnMADS30 NnMADS26 NnMADS31 NnMADS27 NnMADS29 NnMADS33 NnMADS32 NnMADS34 NnMADS28 NnMADS41 NnMADS38 NnMADS40 NnMADS37 NnMADS39 NnMADS43 NnMADS42 Consensus
GRVKIKMEFIDNKLRRYTTFS KRKTGIMKKAYELSTLTGTQVLLLVAS ETGHVYTFATR 59 GRQK IE I KR IDREDCRNVTFS KRKS G IFKKAS DLVTLCGAETAI I MFS P GGNAFS FHP 59

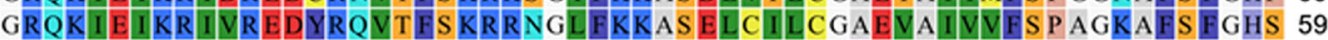
GRKK I I IS I I KLKKHLQVTF S KRRGGLFKKAS ELC ILCGVE I AV IV VF P AGKLF S FGHS 59 GRRK IQ IAK IT TKDRLHVTFS KRRAGLFNKAC ELCILCGAEVAVI VFS P AGKAFS FGHP 59 GKRR I I I EK I ERNERRQVTFCKRRKGLF QKAADLCLLCDVKVAVVVVF S P AGRP YI F GHP 59 GRRR I I IEK I ECKEKLNVCFS KGRTGLFKKAKKLDDLS GSKTVI I I F P AGKVFT FGDP 59 GRRR I I EK I ECKEKLNVCF S KRRTGLFKKAKKLDDLS GSKTAT I IF SPAGKVFT FGDP 59 GRRR IKI IEK I GCKEKLNVCFS KRRTGLFKKAKKLDDLS GSKTAII I IFS P AGKVFT YGDP 59 GRRR IKXEKI IECKDKLNVCFS KRR TGLFKKAKKLDDLS GS XTAIIIIIFS PAGKVFTFGDP 59 ARKKVKLALI ANES ARRT T FKKRKNGLMKKVS ELLSTLCGVS ACAII IYS P YDKQP DVWWPS 59 ARKKVKLALI ANETARKAT FKKRKKGLMKKVS ELS TLCGVS ACA I I YS P YDS QP DVWP S 59 PRAKTQHMLIIADPRVRKVTFEKRMKG GTKKLS DLS TLCGVDACAII YS P YNKQP DVWPS 59 PRGS GGPRGKVKLEQ IADP CNRKTS FKKRKKNLFKKVQELGS LCGVS ACAII IYGP YDTK 59 AGKKVKF AL IS NES AR - T T FKKRKNGLMKNVS ELS TLCGVS ACAII I YS LY GKCLDVWP S 58 AQSRLAS ES IEYRKARKT - FI KRMQGLKKKMHELT TLCD IEGFII I C FDGLQQS NEDS AM 58 GR GKLKLEFIIS KES S RRT T FRKRMLGLKKKVKEFS TLC GVDACLIVHGLDQGDRP E ICP 59 GRRK IKI EK I EXKEXRNVTFSKRRTGLFKKASELSTLCGVEXA I I I FSPAGKVFTFGHP

Fig. 3 (See legend on next page.) 
(See figure on previous page.)

Fig. 3 Conservative analysis on MADS-box domain among different NnMADS proteins. a MADS-box MEF like alignment. b MADS-box SRF like alignment. HsMEF2A, HsMEF2B, HsMEF2C, HsMEF2D and SRF sequences were retrieved from Homo sapiens database as reference. Protein sequences correspond to the conserved regions on all NnMADS. In the consensus line, uppercase letters represent identity in more than $50 \%$ of sequences and $X$ represents less than $50 \%$ identity. The red box marked letters indicate the specific residues involved in a conserved feature (referred to MEF and SRF domain from NCBI)

subcellular localization analysis. All of them were localized in the nuclear (Fig. 5). Interestingly, the GFP signals of NnMADS1 were also localized in the cytomembrane (Fig. 5).

\section{Overexpression of NnMADS14 in Arabidopsis}

It is known that E-class genes are necessary for the genesis of each floral organ, including petal, stamen, and pistil [14]. All the floral organs display a sepal-like phenotype in Arabidopsis E-class genes triple mutant spe1spe2spe3. And in tetra-mutant of spe1spe2spe3spe4, all the floral organs were transited into leaf-like organs [16]. In lotus, there are three E-class MADS-box genes which include NnMADS7, NnMADS8, and NnMADS14. According to their expressional patterns, NnMADS14 was the only one showing floral organ specificity because the former two both had high expression in root and rhizome (Fig. 4). Therefore, we selected NnMADS14 as the candidate gene to verify its function in Arabidopsis. The NnMADS14 driven by $35 \mathrm{~S}$ promoter construct was transformed into Arabidopsis (Col-0). A total of 10 transgenic lines were obtained, among which two of the T3 lines showed an early flowering phenotype (Fig. 6a). The expression of NnMADS14 gene was then checked in these two lines, which was confirmed to be overexpressed (Fig. 6a). Besides early flowering, the overexpression lines also showed phenotypes of transition from leaf to floral organ (Fig. 6b, c) and formation of double pistils or double flowers (Fig. 6d-i).

To explore the underlying mechanisms of these phenotypes, we then checked the expression of several key genes, including AtLFY, AtAP1, AtAG, and AtFT, that regulate the flowering time and inflorescence formation in the two Arabidopsis NnMADS14 overexpression lines. The qRT-PCR results showed that the expression of both AtLFY and AtAP1 genes were dramatically increased along with the overexpression of NnMADS14, whereas AtAG and AtFT had only a tiny increase in their expression (Fig. 6j).

\section{Expression of NnMADS14 in different lotus strains}

Based on the phenotype of Arabidopsis NnMADS14 overexpression lines, it seems that the expression level of this gene is positively related to the flowering and floral organogenesis. To confirm if it is also true in lotus, six different lotus strains were selected to analyze the expression of NnMADS14 gene. These strains displayed different flowering time and flower shapes (Fig. 7a, b). qRT-PCR results showed that NnMADS14 gene was expressed in the flower buds of all the strains (Fig. 7c). However, the expression levels were higher in the strains showing either longer flowering time or pistil petaloid (Fig. 7c).

\section{Discussion}

Because of its importance in plant floral organ and fruit development, MADS-box gene family has gained increasing attention from the scientific community. Todate, MADS-box genes have been systematically characterized in more than 34 different plant species [11, 22, 39-42]. Through searching against the released genome database of $N$. nucifera 'China Antique' [43], a total of 44 MADS-box genes were determined, whereas only 40 MADS-box genes were annotated in the genome of another wild strain of sacred lotus [44]. This calls for further improvement of lotus genome data, which might lead to the discovery of more NnMADSs. Genes of this family could be sorted into two types with five subtypes. Phylogenetic analysis of these NnMADS genes along with those from Arabidopsis and rice showed that the divergence of different types and sub-types of this gene family occurred before the evolution of these three different plant species. This divergence might have occurred during the genesis of embryophyte or even before (Fig. 1b). Generally, the basal species contain less NnMADS genes than those highly evolved species [54], which seems to be determined by the whole genome duplication (WGD). During evolution, at least two WGD events occurred in Arabidopsis and rice [55, 56], whereas lotus experienced only one WGD with the absence of the $\gamma$ WGD [43, 44]. Ka/Ks ratio approximated to one showed that no selection mutation occurred. These suggested that $N$. nucifera could be considered as a basal plant model for studying the evolution of MADS-box function.

Different with type II genes containing abundant transcript variants, all type I genes belong to monophyletic lineages, which is consistent with the hypothesis that the birth- and death-evolution rate of type I genes is higher than that of type II in angiosperms [57]. Most of the type I genes have a simple structure with only one exon (Fig. 2), which is similar to that in rice, grape, and Arabidopsis [22, 39, 42]. In contrast, structures of type II MADS-box genes are more complicated, with several of them containing more than ten exons (Fig. 2). The protein structures of type II are also more complicated than those of type I. Together, the type II MADS-box genes 
a

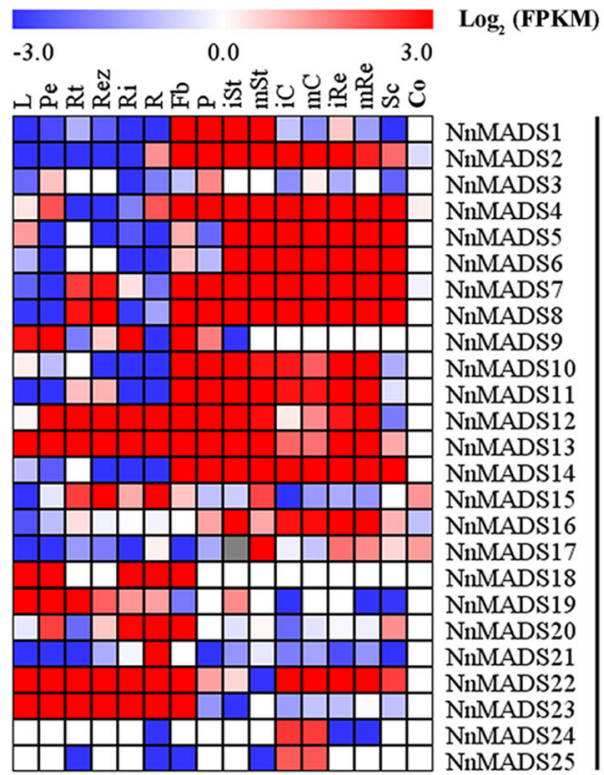

$-3.0 \quad \log _{2}$ (FPKM)

$0.0 \quad 3.0$

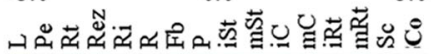
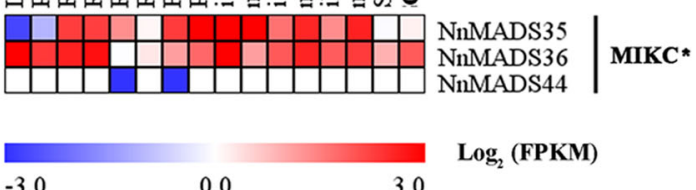

$\begin{array}{lll}-3.0 & 0.0 & 3.0\end{array}$

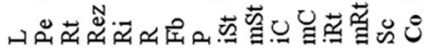

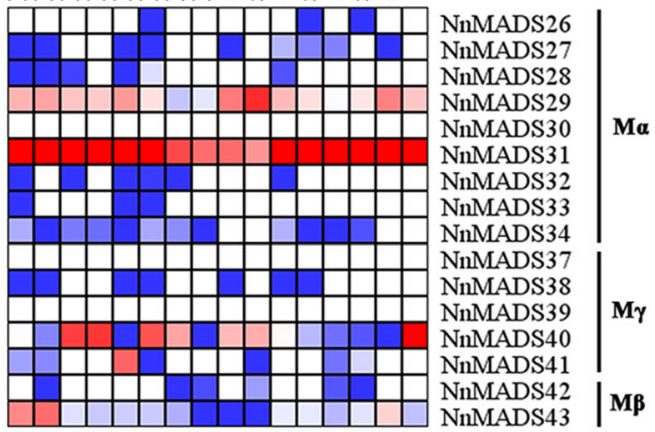

b

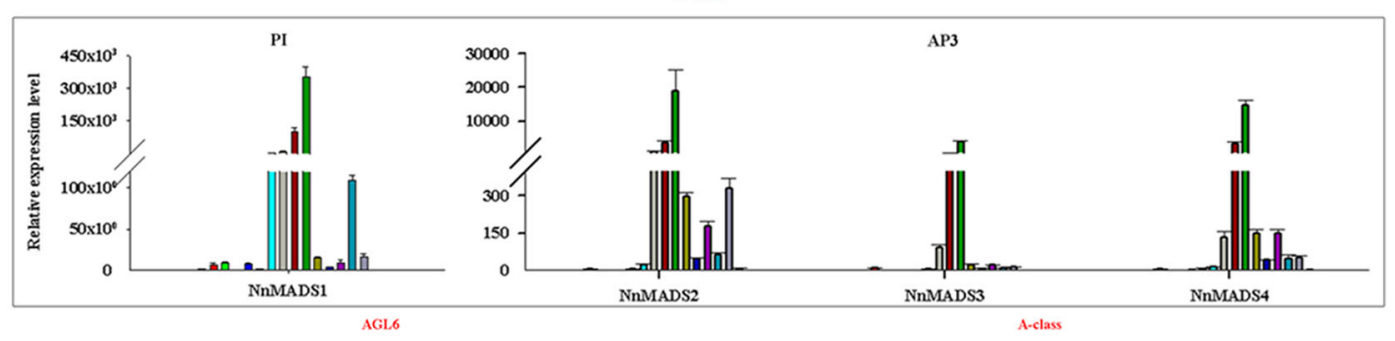

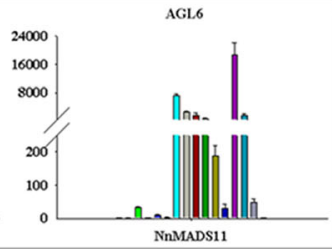
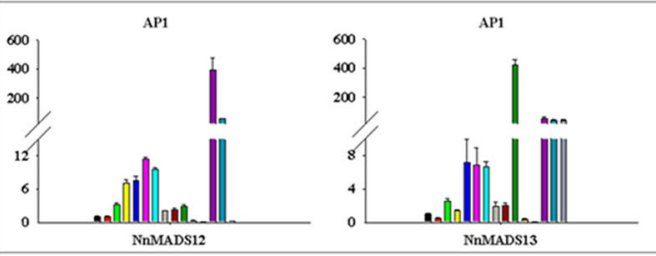

E-class
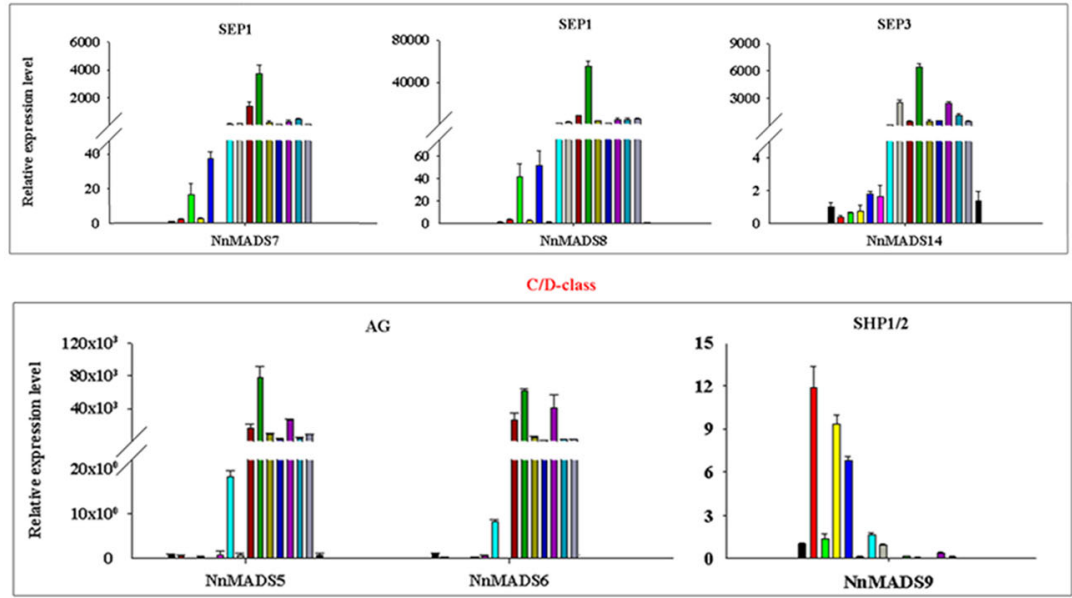

AG

C/D-class

Fig. 4 (See legend on next page.) 
(See figure on previous page.)

Fig. 4 The expressional patterns of NnMADS genes in different tissues of N. nucifera. a The left panel shows the MIKC ${ }^{\mathcal{C}}$ sub-type members of type II MADS box genes; the upper panel of right side shows MIKC* sub-type members of type II MADS box genes, and the lower panel of the right side shows those of the type I. The FPKM values were collected from the online data as mentioned in M\&M, and used for drawing the heatmap. $\mathbf{b}$ qRT-PCR analysis on the relative expressions of 14 representative NnMADS genes in different tissues of $N$. nucifera. Transcript level of each NnMADS were first normalized to those of the housekeeping gene NnActin and then compared to the expression level of each gene in leaf. Data are means \pm SD $(n=3)$. L: Leaf; Pe: Petiole; three parts of the rhizome, such as Rt: rhizome tip, Rez: Rhizome elongation zone, Ri: Rhizome internode; R: Root; Fb: Flower bud; P: Petal; Being collected stamen, carpel, receptacle before pollination named as immature stamen (iSt), immature carpel (iC), immature receptacle (iRe); Being collected stamen, carpel, receptacle after pollination named as mature stamen (mSt), mature carpel (mC), mature receptacle (mRe); Sc: Seed coat; Co: Cotyledon

might be subjected to more intricate regulation. Along with previous reports, it also indicated that type II genes might be functionally more important than type I genes for plants, although some of type I genes were shown to play important regulatory roles in plant reproduction as well $[58,59]$.

Among the type II genes, MIKC ${ }^{\mathrm{c}}$ sub-type is best known for its plant specific and importance for floral organogenesis. The phylogenetic analysis showed that genes of this sub-type could be further divided into 12 clades (Fig. 1b), with the FLC clade being absent in both lotus and rice. It is known that the $F L C$ genes regulate the flowering time through controlling vernalization and vernalization-independent pathways [60]. It seems that the FLC clade is absent in plant species, including rice, cotton, and orchid, that do not require vernalization for flowering [39, 41, 61]. This suggests that lotus does not require vernalization for flowering.

At least 14 NnMADSs belong to the well-known classic 'ABCDE' model genes in plant [5-11], which consists of class A (AP1/FUL), class B (AP3/PI), class C/D (AG/ STK/SHP1/2), and class E (SEP1/2/3/4) $[9,13,16]$. Most of the 'ABCDE' model genes displayed a floral organ preferential expression pattern (Fig. 4), indicating their potential roles in the floral organogenesis of lotus. Subcellular localization of representative members of A, B, $\mathrm{C} / \mathrm{D}$, and $\mathrm{E}$ class genes verified their nuclear localization (Fig. 5). Because the $\mathrm{E}$ class genes are important for the development of each floral organ based on the 'ABCDE' model, one of its homolog in lotus NnMADS14 was selected for functional characterization in Arabidopsis, which proved its importance in floral organogenesis (Fig. 6). The result suggests that NnMADS14 functions mainly through regulating the expression of $L F Y$ and $A P 1$ genes. Although there is still no stable transformation system for lotus, the expression of NnMADS14 gene among different lotus germplasm verified that this gene is highly related to the flowering time and floral organogenesis in lotus (Fig. 7). Similar functions of $S E P$-like genes in floral organ formation were also proved in many other plants, such as Phalaenopsis orchid, Prunus mume, and soybean [62-64]. In strawberry (that develops from the receptacle of the flower) SEP1/2 homolog FaMADS9 plays an important role in receptacle development and regulates ripening programs $[23,65]$.

\section{Conclusions}

In conclusion, a genome-wide search identified a total of 44 MADS-box genes in the lotus genome. Phylogenetic analysis showed the potential divergence time of MADSbox gene family, and the lack of $F L C$ clade in plant species that do not require vernalization. Systematic analyses on their expressional patterns and subcellular localization showed some potential candidates NnMADS genes involved in floral organogenesis. Among them, the function of a homolog of SEPS gene NnMADS14 was verified in Arabidopsis system, along with its expression in different lotus germplasm showing obvious difference in flowering time and flower shape. The comprehensive information on lotus MADS-box gene family might help to further understand the mechanism underlying its floral organ development, and hence contribute to the breeding of high value ornamental lotus.

\section{Methods}

Plant materials, RNA extraction, and CDNA synthesis Nelumbo nucifera cultivar 'China Antique' (named by Prof. Guozheng Huang) was grown in experimental pools in Wuhan, China $\left(30^{\circ} 32^{\prime} 45^{\prime \prime N} 114^{\circ} 24^{\prime} 52^{\prime \prime} \mathrm{E}\right)$ by the authors, which is identical with the sequenced one [43], and has been cultivated for several decades in Wuhan Botanical Garden, Chinese Academy of Sciences. The 16 tissues included leaf, petiole, rhizome (including tip, elongation zone, and internode), root, flower bud, petal, stamen (immature and mature), carpel (immature and mature), receptacle (immature and mature), and seed (seed coat and cotyledon) were collected before 10:00 am in July. For sample harvesting, it is unnecessary to obtain any permission from any authority. All the samples were frozen with liquid nitrogen immediately after harvesting, and then kept in $-80^{\circ} \mathrm{C}$ freezer until used for RNA extraction.

The RNA reagent (OminiPlant RNA Kit, CWBIO, China) was used to extract the total RNAs. During extraction, genomic DNA was removed with RNase-free 





(See figure on previous page.)

Fig. 5 Subcellular localization of six representative NnMADSs fused with green fluorescent protein. NnMADSs were constructed into plasmid with fusions of GFP and driven by the CaMV35S promoter. DAPI was used to mark nuclei. Panels from left to right refer to GFP, Bright, DAPI, and Merged images, respectively. Protein fusions co-localized with DAPI markers are marked with red arrows. The boxes are enlarged images for cytomembranes. Scale bars $=25 \mu \mathrm{m}$

DNase I (Thermo, Shanghai, China). The RNAs were reversed with HiScript II One Step RT-PCR Kit (Vazyme, China) to synthesize complementary DNAs (cDNAs) synthesis according to instructions of the Kit.

\section{Database search and identification of MADS-box family genes in lotus}

MADS-box protein sequences of Arabidopsis and rice were retrieved from TAIR (http://www.arabidopsis.org/) and Rice Genome Annotation Project (http://rice.plantbiology.msu.edu/), respectively. N.nucifera MADS-box protein sequences were obtained from the lotus database (http://lotus-db.wbgcas.cn/) and were blasted in NCBI to get the full-length CDS and genomic sequence. To confirm and identify the putative $N$. nucifera MADS-box genes, SRF-TF domain (PF00319) retrieved from Pfam 31.0 (http://pfam.xfam.org/) was searched against the hidden Markov model (HMM, https://www.ebi.ac.uk/ Tools/hmmer/search/phmmer). The detailed information is shown in Table S1. MADS-box sequences from other species used in this study were obtained from previous researches $[40,41,52]$. The evolutionary relationships among these species were constructed using the taxonomy tool in NCBI (https://www.ncbi.nlm.nih.gov/ Taxonomy/CommonTree/wwwcmt.cgi) and the phylip tree format was downloaded. Then, the phylip tree was generated by phylip software version 3.695 (http://evolution.genetics.washington.edu/phylip/getme-new1.html).

\section{Construction of physical map and phylogenetic analysis}

The open accessed software Mapchart (v2.3.2) was used to analyze distribution of $M A D S$-box genes in the lotus genome, specifically in the top ten biggest megascaffolds [66]. Multiple sequences were aligned by MUSCLE using default parameters [67]. The phylogenetic trees were constructed by the neighbor-joining (NJ) algorithm using MEGA7.026 [68] with the Jones-taylor-thomton (Jtt) model. The bootstrap method was applied in phylogeny test with 1000 replications. The gaps and missing data treatment were set using the pair-wise
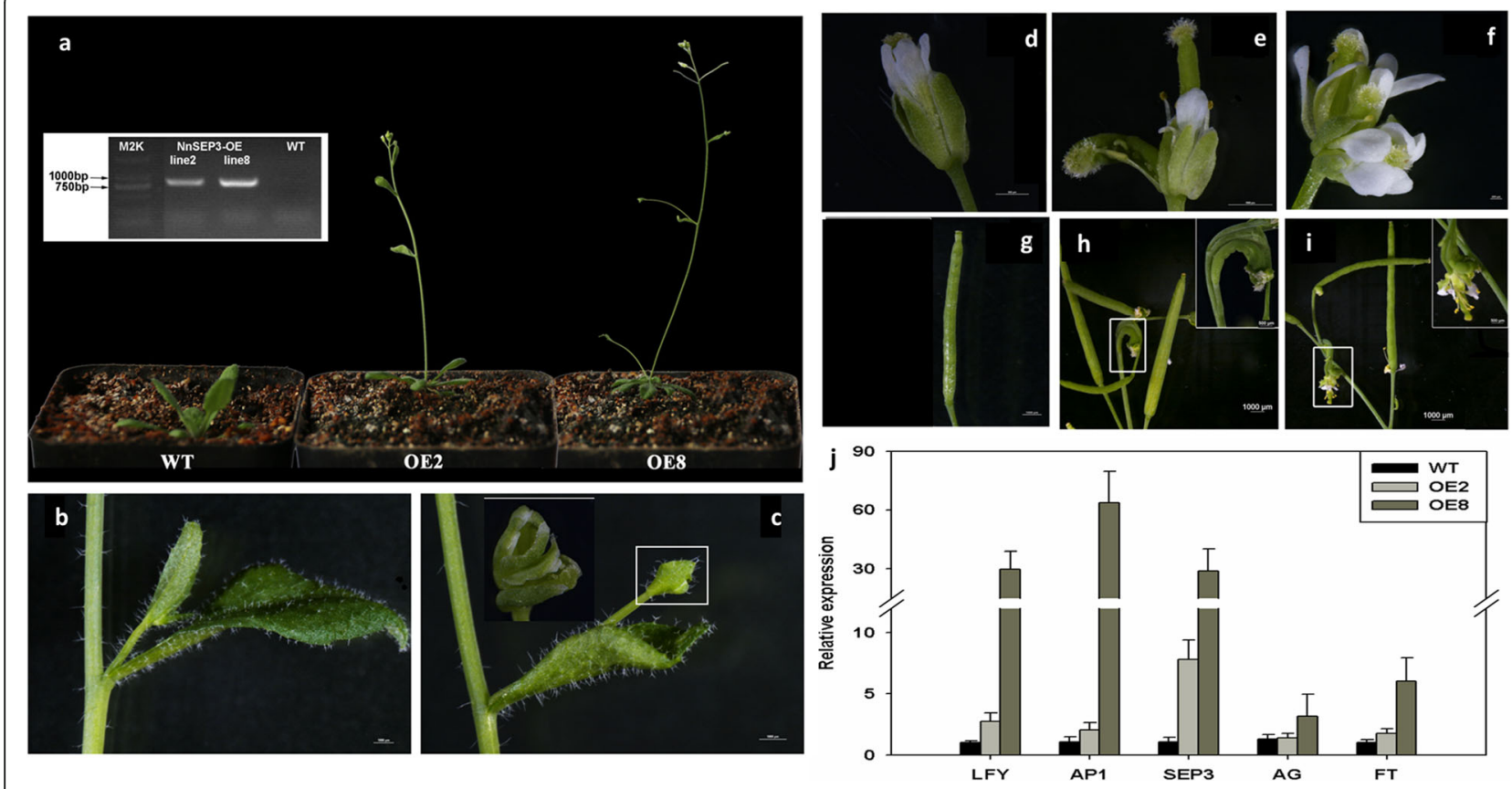

Fig. 6 Phenotyping of 35S:NnSEP3 transgenic Arabidopsis. a Early flowering of two transgenic Arabidopsis lines. The inserted panel shows the overexpression of NnSEP3 in the two lines (OE2 and OE8). b Cauline leaf of wide type Arabidopsis. c Transition of cauline leaf to flower in 35S:NnSEP3 transgenic Arabidopsis. The inserted panel shows the transitional flower. $\mathbf{d}$ Normal flower in wide type Arabidopsis. e Flower with two pistils in the OE2 line. $\mathbf{f}$ Transition of single flower into double flowers with two pistils in the OE8 line. $\mathbf{g}$ Normal silique in wide type Arabidopsis. (h, i) Aberrant silique of OE2 (h) and OE8 (i) lines. The inserted panels show the enlarged images of the area in the white rectangles. Bars are $500 \mu \mathrm{m}$. $\mathbf{j}$ Expression analysis of the endogenous flowering and leaf development-related genes in Arabidopsis. WT: wide type, OE: 35S::NnSEP3. LFY, AP1, SEP3, AG, and FT were analyzed by qRT-PCR in leaves 



Fig. 7 Expression analysis of NnSEP3 gene in the flower bud of different lotus strains. a Flower of the longer flowering lotus in late autumn. The flowering time expand from June to November. b Flowers of different lotus species. c Expression levels of NnSEP3 gene among different strains. I, longer flowering lotus; II, ordinary lotus; III, strain with stamen petaloid; IV, strain with ovary petaloid; V, all-double-petalled-flower strain; VI, strain with multi- all-double-petalled-flowers in one flower bud

deletion option to certify the dissimilatory regions that could generate the topology of NJ tree.

\section{Analysis of MADS-box genes' structure and duplication} The lotus MADS-box family protein sequences were analyzed using the MEME software version 5.0.1 (http://meme-suite. org/doc/cite.html) [69]. The parameters were set as follows: repetitions could be any number, maximum number of motifs $=20,6 \leq$ width $\leq 200$. SMART tool (http://smart.emblheidelberg.de/) was used to confirm the MEME motifs. ClustalX software and CLC Sequence Viewer 8.0.0 software (https://www. qiagenbioinformatics.com/products/ clc-sequence-viewer-directdownload/) were used to conduct the multiple sequence alignments, and generated the image. Using the Gene Structure Display Server tool (http://gsds.cbi.pku.edu.cn), the exon/intron gene structure was carried out with mapping the CDSs to genomic sequences (without UTR). Potential gene duplications with major standard analysis were conducted as follows: (1) length of sequence alignment covers longer gene more than $75 \%$, and (2) identity of the alignment being more than $75 \%$ [70]. The values of $K a$ and $K s$ were performed by TBtools (https://github.com/ CJ-Chen/TBtools) [71].

\section{Expression analysis using $N$. nucifera RNA-seq data}

For the expression profile of $N$. nucifera MADS-box genes, RNA-seq data was downloaded from NCBI SRA (PRJNA492157, PRJNA503979, and PRJNA428028) and lotus database (http://lotus-db.wbgcas.cn/), and then used for analysis. Sixteen tissues, including leaf, petiole, tip, elongation zone, internode, root, flower bud, petal, immature anther, mature-anther, immature carpel, mature carpel, immature receptacle, mature receptacle, seed coat, and cotyledon were presented by values of FPKM (fragments per kilobase of exon model per million mapped reads) (Fig. S3, Table S4). Mev software version 4.9.0 was used to generate the heat-map of expression of NnMADS genes.

Analysis of gene expression by quantitative real-time PCR Homologous classic $\mathrm{ABC}(\mathrm{D}) \mathrm{E}$ model genes were picked out from the MADS-box family in lotus as candidate genes. Fourteen MADS-box genes were chosen to quantify the transcription levels in different tissues. Actin was used as an internal control. The primer sets are listed in Table S6. The qRT-PCR reactions were performed using the SYBR Green Master Mix (BioRad, http://www.bio- 
rad.com/) as previously described [51]. Three biological replicates, each with three technical repeats, were analyzed. And the relative gene expression was calculated by $2^{-\Delta \Delta C t}$ comparative threshold cycle $(\mathrm{Ct})$ method [72]. The data were indicated as mean \pm SD.

\section{Transgenic and subcellular localization analysis}

The candidate MADS-box family members coding domain sequence (CDS) were amplified from $N$. nucifera cDNA via PCR using high-fidelity thermostable DNA polymerase. The primers for these genes were designed with Primer Premier 5.0. The PCR products were cloned into $\mathrm{pMD}^{\circ} 18-\mathrm{T}$ vector (TaKaRa). For sequencing, the PCR products were cloned into a vector, and then transformed into DH5 $\alpha$ E.coli cells. For Nicotiana transformation, they were cloned into pMDC83 vector fused with GFP and driven by CaMV $35 \mathrm{~S}$ promoter. The primers are listed in Table S6. The recombinant plasmids were isolated and used to transform tobacco leaf according to the protocol described by Sparkes et al. [73]. After infiltration, the plant was allowed to grow for 2 or 3 days, the transformed leaves were observed on a confocal microscope (Leica). The DAPI Staining Solution (Beyotime) was used to stain the nucleus.

For transgenic analysis, the construct 35S::NnSEP3GFP was transformed into Arabidopsis thaliana (Col-0) using Agrobacterium-mediated floral dip method [74]. Arabidopsis thaliana plants were cultivated in a growth chamber maintained at $22^{\circ} \mathrm{C}$ and a $16 \mathrm{~h} / 8 \mathrm{~h}$ (light/dark) photoperiod. The T3 homozygous transgenic lines were used for further study.

\section{Supplementary Information}

The online version contains supplementary material available at https://doi. org/10.1186/s12870-020-02712-w.

Additional file 1: Table S1. MADS-box genes identified in N. nucifera. Table S2. Segmental and tandem duplications of paralogous MADS-box pairs in lotus. Table S3. Categorization of MADS-box genes family in three plant genomes. Table S4. FPKM value of NnMADSs. Table S5. The relative expressions of 14 representative NnMADS genes under qRT-PCR analysis. Table S6. The primers of NnMADS genes in lotus.

Additional file 2: Figure S1. Distribution of MADS-box genes in lotus genome. a Mapping of the NnMADS genes in megascaffold- $1 \sim-10$ of lotus genome. The unit of the length is Mb. $\mathbf{b}$ The number of NnMADS genes in each megascaffold. c The density of MADS-box genes in megascaffold $-1 \sim-10$. The unit is Mb/gene. Figure S2. The correlation analysis of RNA-seq and qRT-PCR data. $\mathbf{a}$ The correlation of fourteen MADSbox genes in lotus tissues. b The correlation of NnMADS12 and NnMADS13 after removing two off-line data. The low expression or not detected data were not considered. Figure S3. The different tissues of $N$. nucifera. L: Leaf; four parts of rhizome, such as Pe: Petiole, Rt: rhizome tip, Rez: Rhizome elongation zone, Ri: Rhizome internode; R: Root; Fb: Flower bud; P: Petal; St: Stamen; C: carpel; iRe: immature Receptacle; mRe: mature Receptacle; Sc: Seed coat; Co: Cotyledon.

\section{Abbreviations}

AG: Agamous; AP: Apetala; CDS: Coding Domain Sequence; DEF: Deficiens; Ct: Threshold Cycle; FLC: Flowering Locus; FPKM: Fragments per Kilobase of
Exon Model per Million Mapped Reads; FUL: Fruitful; MADS: MCM1, AG, DEF and SRF; MAF1/FLM: Mads affecting flowering; MCM1: Minichromosome maitenance; MEF: Myocyte enhacer factor; NnMADS: Nelumbo nucifera MADS; PI: Pisittala; qRT-PCR: Quantitative Real-Time PCR; SEP: Sepallata;

SHP: Shatterproof; SOC: Suppressor of overexpression of constans;

SRF: Serum response factor; STK: Seedstick; VP: Short vegetative phase;

TT16: Transparent testa16; WGD: Whole genome duplication

\section{Acknowledgements}

We appreciate Dr. Xianpeng Yang from Wuhan botanical garden, CAS, and Dr. Xianzhen Yin from Institute of Genetics and Development Biology, CAS for kindly providing the vectors used in this study.

\section{Authors' contributions}

Z. L. and P. Y. designed the experiments and wrote the manuscript, Z. L. and D. C. conducted the experiments, Z. L. and R. N. D. analyzed the data. All authors have read and approved the manuscript.

\section{Funding}

There is no funding support for this study.

\section{Availability of data and materials}

All data generated or analyzed during this study are included in this published article and its supplementary information files.

Ethics approval and consent to participate

Not applicable.

\section{Consent for publication}

Not applicable.

\section{Competing interests}

The authors declare that they have no competing interests.

\section{Author details}

${ }^{1}$ State Key Laboratory of Biocatalysis and Enzyme Engineering, School of Life Sciences, Hubei University, Wuhan 430062, China. ${ }^{2}$ Institute of Oceanography, Minjiang University, Fuzhou 350108, China.

Received: 7 July 2020 Accepted: 20 October 2020

Published online: 29 October 2020

\section{References}

1. Wang Q, Zhang X. Colored illustration of lotus cultivars in China. Beijing: China Forestry Publishing House; 2005.

2. Kubo N, Hirai M, Kaneko A, Tanaka D, Kasumi K. Development and characterization of simple sequence repeat (SSR) markers in the water lotus (Nelumbo nucifera). Aquat Bot. 2009;90(2):191-4.

3. Shen-Miller J. Sacred lotus, the long-living fruits of China antique. Seed Sci Res. 2007:12(3):131-43.

4. Yanofsky MF, Ma H, Bowman JL, Drews GN, Feldmann KA, Meyerowitz EM The protein encoded by the Arabidopsis homeotic gene agamous resembles transcription factors. Nature. 1990;346(6279):35-9.

5. Causier B, Schwarz-Sommer Z, Davies B. Floral organ identity: 20 years of ABCs. Semin Cell Dev Biol. 2010;21(1):73-9.

6. Dodsworth S. Petal, sepal, or tepal? B-genes and monocot flowers. Trends Plant Sci. 2016:1

7. Irish V. The ABC model of floral development. Curr Biol. 2017;27(17):R887.

8. Theißen G, Melzer R, Rümpler F. MADS-domain transcription factors and the floral quartet model of flower development: linking plant development and evolution. Development. 2016;143(18):3259-71.

9. Coen ES, Meyerowitz EM. The war of the whorls: genetic interactions controlling flower development. Nature. 1991;353(6339):31-7.

10. WeigelD MEM. The ABCs of floral homeotic genes. Cell. 1994;78(2):203

11. Liu J, Fu X, Dong Y, Lu J, Ren M, Zhou N, et al. MIKC $C^{C}$-type MADS-box genes in Rosa chinensis: the remarkable expansion of ABCDE model genes and their roles in floral organogenesis. Hortic Res. 2018;5(1):25.

12. Wellmer $F$, Graciet $E$, Riechmann JL. Specification of floral organs in Arabidopsis. J Exp Bot. 2014;65(1):1-9. 
13. Pinyopich A, Ditta GS, Savidge B, Liljegren SJ, Baumann E, Wisman E, et al. Assessing the redundancy of MADS-box genes during carpel and ovule development. Nature. 2003;424:85.

14. Pelaz S, Ditta GS, Baumann E, Wisman E, Yanofsky MF. B and C floral organ identity functions require SEPALLATA MADS-box genes. Nature. 2000; 405(6783):200.

15. Kaufmann K, Melzer R, Theissen G. MIKC-type MADS-domain proteins: structural modularity, protein interactions and network evolution in land plants. Gene. 2005;347(2):183.

16. Ditta G, Pinyopich A, Robles P, Pelaz S, Yanofsky MF. The SEP4 gene of Arabidopsis thaliana functions in floral organ and meristem identity. Curr Biol. 2004;14(21):1935-40.

17. Schilling S, Pan S, Kennedy A, Melzer R. MADS-box genes and crop domestication: the jack of all traits. J Exp Bot. 2018;69(7):1447-69.

18. Yan W, Chen D, Kaufmann K. Molecular mechanisms of floral organ specification by MADS domain proteins. Curr Opin Plant Biol. 2016;29:154-62.

19. Gramzow L, Ritz MS, Theißen G. On the origin of MADS-domain transcription factors. Trends Genet. 2010;26(4):149-53.

20. Alvarez-Buylla ER, Pelaz S, Liljegren SJ, Gold SE, Burgeff C, Ditta GS. Ribas de Pouplana L, Martínez-Castilla L, Yanofsky MF: An ancestral MADS-box gene duplication occurred before the divergence of plants and animals. Proc Natl Acad Sci. 2000;97(10):5328-33.

21. Henschel K, Kofuji R, Hasebe M, Saedler H, Münster T, Theißen G. Two ancient classes of MIKC-type MADS-box genes are present in the moss Physcomitrella patens. Mol Biol Evol. 2002;19(6):801-14.

22. Parenicová L, de Folter S, Kieffer M, Horner DS, Favalli C, Busscher J, et al Molecular and phylogenetic analyses of the complete MADS-box transcription factor family in Arabidopsis: new openings to the MADS world. Plant Cell. 2003;15(7):1538-51.

23. Smaczniak C, Immink RGH, Angenent GC, Kaufmann K. Developmental and evolutionary diversity of plant MADS-domain factors: insights from recent studies. Development. 2012;139(17):3081-98.

24. Verelst W, Saedler H, Münster T. MIKC* MADS-protein complexes bind motifs enriched in the proximal region of late pollen-specific Arabidopsis promoters. Plant Physiol. 2007;143(1):447-60.

25. Royo C, Torres-Pérez R, Mauri N, Diestro N, Cabezas JA, Marchal C, et al. The major origin of seedless grapes is associated with a missense mutation in the MADS-box gene VviAGL11. Plant Physiol. 2018;177(3):1234-53.

26. Wu F, Shi X, Lin X, Liu Y, Chong K, Theißen G, et al. The ABCs of flower development: mutational analysis of AP1/FUL-like genes in rice provides evidence for a homeotic (a)-function in grasses. Plant J. 2017;89(2):310-24

27. Morel P, Heijmans K, Ament K, Chopy M, Trehin C, Chambrier P, et al. The floral $C$-lineage genes trigger nectary development in petunia and Arabidopsis. Plant Cell. 2018.

28. Zhang G, Xu N, Chen H, Wang G, Huang J. OsMADS25 regulates root system development via auxin signalling in rice. Plant J. 2018;95:1004-22.

29. Guo X, Chen G, Naeem M, Yu X, Tang B, Li A, et al. The MADS-box gene SIMBP11 regulates plant architecture and affects reproductive development in tomato plants. Plant Sci. 2017;258:90-101.

30. Lee J, Lee I. Regulation and function of SOC1, a flowering pathway integrator. J Exp Bot. 2010;61(9):2247-54.

31. Liu C, Chen H, Er HL, Soo HM, Kumar PP, Han JH, et al. Direct interaction of AGL24 and SOC1 integrates flowering signals in Arabidopsis. Development. 2008;135(8):1481-91.

32. Lee JH, Ryu H-S, Chung KS, Posé D, Kim S, Schmid M, et al. Regulation of temperature-responsive flowering by MADS-box transcription factor repressors. Science. 2013;342(6158):628-32.

33. Michaels SD, Amasino RM. FLOWERING LOCUS C encodes a novel MADS domain protein that acts as a repressor of flowering. Plant Cell. 1999;11(5):949-56.

34. Adamczyk BJ, Lehti-Shiu MD, Fernandez DE. The MADS domain factors AGL15 and AGL18 act redundantly as repressors of the floral transition in Arabidopsis. Plant J. 2007;50(6):1007-19.

35. Nesi N, Debeaujon I, Jond C, Stewart AJ, Jenkins Gl, Caboche M, et al. The TRANSPARENT TESTA16 locus encodes the ARABIDOPSIS BSISTER MADS domain protein and is required for proper development and pigmentation of the seed coat. Plant Cell. 2002;14(10):2463-79.

36. Dreni $\mathrm{L}$, Zhang D. Flower development: the evolutionary history and functions of the AGL6 subfamily MADS-box genes. J Exp Bot. 2016;67(6):1625-38.

37. Tapia-Lopez R, Garcia-Ponce B, Dubrovsky JG, Garay-Arroyo A, Perez-Ruiz RV Kim SH, et al. An AGAMOUS-related MADS-box gene, XAL1 (AGL12), regulates root meristem cell proliferation and flowering transition in Arabidopsis. Plant Physiol. 2008;146(3):1182-92.

38. Yu LH, Miao ZQ, Qi GF, Wu J, Cai XT, Mao JL, et al. MADS-box transcription factor AGL21 regulates lateral root development and responds to multiple external and physiological signals. Mol Plant. 2014;7(11):1653-69.

39. Arora R, Agarwal P, Ray S, Singh AK, Singh VP, Tyagi AK, et al. MADS-box gene family in rice: genome-wide identification, organization and expression profiling during reproductive development and stress. BMC Genomics. 2007;8:21.

40. Duan W, Song X, Liu T, Huang Z, Ren J, Hou X, et al. Genome-wide analysis of the MADS-box gene family in Brassica rapa (Chinese cabbage). Mol Gen Genomics. 2015;290(1):239-55.

41. Lin CS, Hsu CT, Liao DC, Chang WJ, Chou ML, Huang YT, et al. Transcriptome-wide analysis of the MADS-box gene family in the orchid Erycina pusilla. Plant Biotechnol J. 2016;14(1):284-98.

42. Grimplet J, Martinez-Zapater JM, Carmona MJ. Structural and functional annotation of the MADS-box transcription factor family in grapevine. BMC Genomics. 2016;17:23

43. Ming $R$, VanBuren $R$, Liu $Y$, Yang $M$, Han $Y$, Li L-T, et al. Genome of the long-living sacred lotus (Nelumbo nucifera Gaertn.). Genome Biol. 2013; 14(5):R41.

44. Wang Y, Fan G, Liu Y, Sun F, Shi C, Liu X, et al. The sacred lotus genome provides insights into the evolution of flowering plants. Plant J. 2013;76(4): 557-67.

45. Hudson KA, Hudson ME. The basic helix-loop-helix transcription factor family in the sacred lotus, Nelumbo nucifera. Trop Plant Biol. 2014;7(2):65-70.

46. Deng J, Fu Z, Chen S, Damaris RN, Wang K, Li T, et al. Proteomic and epigenetic analyses of lotus (Nelumbo nucifera) petals between red and white cultivars. Plant Cell Physiol. 2015;56(8):1546-55.

47. Wang Y, Shi SL, Zhou Y, Zhou Y, Yang J, Tang XQ. Genome-wide identification and characterization of GRAS transcription factors in sacred lotus (Nelumbo nucifera). Peerj. 2016:4:18.

48. Kong DZ, Shen XY, Guo B, Dong JX, Li YH, Liu YP. Cloning and expression of an APETALA1-like gene from Nelumbo nucifera. Genet Mol Res. 2015;14(2):6819-29.

49. Yoo MJ, Soltis PS, Soltis DE. Expression of floral MADS-box genes in two divergent water lilies: Nymphaeales and Nelumbo. Int J Plant Sci. 2010; 171(2):121-46.

50. Wang K, Deng J, Damaris RN, Yang M, Xu L, Yang P. LOTUS-DB: an integrative and interactive database for Nelumbo nucifera study. Database (Oxford). 2015;2015:bav023.

51. Deng J, Li M, Huang L, Yang M, Yang P. Genome-wide analysis of the R2R3 MYB subfamily genes in lotus (Nelumbo nucifera). Plant Mol Biol Report. 2016;34(5):1016-26.

52. Li C, Wang Y, Xu L, Nie S, Chen Y, Liang D, et al. Genome-wide characterization of the MADS-box gene family in radish (Raphanus sativus $L$. ) and assessment of its roles in flowering and floral organogenesis. Front Plant Sci. 2016;7:1390.

53. Zhang Y, Nyong'A TM, Shi T, Yang P. The complexity of alternative splicing and landscape of tissue-specific expression in lotus (Nelumbo nucifera) unveiled by Illumina- and single-molecule real-time-based RNA-sequencing. DNA Res. 2019;26(4):301-11.

54. Gramzow L, Weilandt L, Theißen G. MADS goes genomic in conifers: towards determining the ancestral set of MADS-box genes in seed plants. Ann Bot. 2014;114(7):1407-29.

55. Paterson AH, Bowers JE, Chapman BA. Ancient polyploidization predating divergence of the cereals, and its consequences for comparative genomics. Proc Natl Acad Sci. 2004;101(26):9903-8

56. Yu J, Wang J, Lin W, Li S, Li H, Zhou J, et al. The genomes of Oryza sativa: a history of duplications. PLoS Biol. 2005;3(2):e38.

57. Nam J, Kim J, Lee S, An G, Ma H, Nei M. Type I MADS-box genes have experienced faster birth-and-death evolution than type II MADS-box genes in angiosperms. Proc Natl Acad Sci. 2004;101(7):1910-5.

58. Bemer M, Heijmans K, Airoldi C, Davies B, Angenent GC. An atlas of type MADS box gene expression during female gametophyte and seed development in Arabidopsis. Plant Physiol. 2010;154(1):287-300.

59. Masiero S, Colombo L, Grini PE, Schnittger A, Kater MM. The emerging importance of type I MADS box transcription factors for plant reproduction. Plant Cell. 2011;23(3):865-72.

60. Michaels SD, Amasino RM. Loss of FLOWERING LOCUS C activity eliminates the late-flowering phenotype of FRIGIDA and autonomous pathway 
mutations but not responsiveness to vernalization. Plant Cell. 2001;13(4): 935-41.

61. Nardeli S, Artico S, Aoyagi G, de Moura S, da Franca ST, Grossi-de-Sa M, et al. Genome-wide analysis of the MADS-box gene family in polyploid cotton (Gossypium hirsutum) and in its diploid parental species (Gossypium arboreum and Gossypium raimondii). Plant Physiol Biochem. 2018;127:169-84.

62. Pan Z-J, Chen Y-Y, Du J-S, Chen Y-Y, Chung M-C, Tsai W-C, et al. Flower development of Phalaenopsis orchid involves functionally divergent SEPALL ATA-like genes. New Phytol. 2014;202(3):1024-42.

63. Zhou Y, Xu Z, Yong X, Ahmad S, Yang W, Cheng T, et al. SEP-class genes in Prunus mume and their likely role in floral organ development. BMC Plant Biol. 2017;17:10.

64. Huang F, Xu GL, Chi YJ, Liu HC, Xue Q, Zhao TJ, et al. A soybean MADS-box protein modulates floral organ numbers, petal identity and sterility. BMC Plant Biol. 2014:14:14.

65. Seymour GB, Ryder CD, Cevik V, Hammond JP, Popovich A, King GJ, et al. A SEPALLATA gene is involved in the development and ripening of strawberry (Fragariaxananassa Duch.) fruit, a non-climacteric tissue. J Exp Bot. 2011;62(3):1179-88.

66. Voorrips RE. MapChart: software for the graphical presentation of linkage maps and QTLs. JHered. 2002;93(1):77-8.

67. Edgar RC. MUSCLE: multiple sequence alignment with high accuracy and high throughput. Nucleic Acids Res. 2004;32(5):1792-7.

68. Kumar S, Stecher G, Tamura K. MEGA7: molecular evolutionary genetics analysis version 7.0 for bigger datasets. Mol Biol Evol. 2016;33(7):1870-4.

69. Bailey TL, Boden M, Buske FA, Frith M, Grant CE, Clementi L, et al. MEME suite: tools for motif discovery and searching. Nucleic Acids Res. 2009;37: W202-8.

70. Gu Z, Cavalcanti A, Chen FC, Bouman P, Li WH. Extent of gene duplication in the genomes of drosophila, nematode, and yeast. Mol Biol Evol. 2002; 19(3):256-62.

71. Chen C, Chen H, Zhang Y, Thomas HR, Frank MH, He Y, et al. TBtools: an integrative toolkit developed for interactive analyses of big biological data. Mol Plant. 2020;13(8):1194-202.

72. Livak KJ, Schmittgen TD. Analysis of relative gene expression data using real-time quantitative PCR and the $2^{-\Delta \Lambda C T}$ method. Methods. 2001;25(4): 402-8.

73. Sparkes IA, Runions J, Kearns A, Hawes C. Rapid, transient expression of fluorescent fusion proteins in tobacco plants and generation of stably transformed plants. Nat Protoc. 2006;1:2019.

74. Clough SJ, Bent AF. Floral dip: a simplified method for agrobacteriummediated transformation of Arabidopsis thaliana. Plant J. 1998;16(6):735-43.

\section{Publisher's Note}

Springer Nature remains neutral with regard to jurisdictional claims in published maps and institutional affiliations.

Ready to submit your research? Choose BMC and benefit from:

- fast, convenient online submission

- thorough peer review by experienced researchers in your field

- rapid publication on acceptance

- support for research data, including large and complex data types

- gold Open Access which fosters wider collaboration and increased citations

- maximum visibility for your research: over $100 \mathrm{M}$ website views per year

At BMC, research is always in progress.

Learn more biomedcentral.com/submissions 